\title{
Association between serum 25-hydroxy vitamin D level and gastric adenocarcinoma - a cross sectional study
}

\author{
Arulraj Kevin, Amaranathan Anandhi, Subitha Lakshminarayanan, Sathasivam Sureshkumar, \\ Sadishkumar Kamalanathan \\ Jawaharlal Institute of Postgraduate Medical Education and Research, Puducherry, India
}

Gastroenterology Rev 2021; 16 (2): 155-160

DOI: https://doi.org/10.5114/pg.2020.100659

Key words: gastric carcinoma, vitamin D, vitamin D deficiency.

Address for correspondence: Amaranathan Anandhi, Department of Surgery, Jawaharlal Institute of Postgraduate Medical Education and Research, Puducherry, India, phone: 9487781661, e-mail: anandhiramesh76@yahoo.in

\begin{abstract}
Introduction: Vitamin D is found to have anti-cancer properties. Although the preventive role of vitamin D in cancer is proven, its role in gastric cancer is equivocal.

Aim: To evaluate vitamin D deficiency in patients with gastric adenocarcinoma and its relationship with the disease characteristics.

Material and methods: This single-centre, prospective, cross sectional study was carried out from February 2017 to December 2018. Serum 25-hydroxy vitamin D levels of 94 patients with gastric adenocarcinoma and 94 age- and sex-matched healthy controls were estimated. Among cases, vitamin D levels and disease characteristics such as TNM stage, tumour grade, clinical stage and patient demographics were analysed.

Results: The vitamin D levels among cases $(13.83 \pm 5.97 \mathrm{ng} / \mathrm{ml})$ were significantly lower $(p<0.0001)$ than the control group $(29.15 \pm 4.13 \mathrm{ng} / \mathrm{ml})$. Vitamin D deficiency was found in $88 \%$ of cases and in $3 \%$ of controls. Among cases, age, T stage and clinical stage had a significant inverse relationship with vitamin D levels. Cases with distant metastasis and cases with pain had significantly lower levels of vitamin D compared to the cases without distant metastasis and without pain respectively. Other study parameters did not have a significant relationship with vitamin D.

Conclusions: Vitamin D deficiency is associated with occurrence of gastric adenocarcinoma and correlates with the disease severity. However, to assign a causal relationship and to study the beneficial effect of vitamin $D$ in gastric cancer, further research is needed.
\end{abstract}

\section{Introduction}

Gastric carcinoma is the fifth most common cancer worldwide. It is the third most common cause of deaths due to cancer [1]. Vitamin $D$ has been found to have a role in the tumourigenesis of gastric cancer [2]. Vitamin $\mathrm{D}$ is converted to calcitriol, a steroid hormone $\left(1,25(\mathrm{OH})_{2} \mathrm{D}_{3}\right)$. It is produced in the skin utilizing the ultraviolet (UV) radiation in sunlight. Multiple factors such as indoor occupation, avoidance of sunlight, distance from the equator with low levels of sunlight, winter season, clothes that cover the entire body, and dark skin affect vitamin D synthesis and a significant proportion are vitamin $D$ deficient [3]. Anticancer properties of calcitriol include anti-proliferative effects, stimulation of differenti- ation and apoptosis, anti-inflammatory effects, suppression of angiogenesis and metastasis [4]. The anti-tumour effect of vitamin $D$ in gastric cancer found to be mediated by inhibition of DNA polymerase $\alpha$, decreasing expression of cyclin dependent kinase, PTEN up-regulation and inhibition of the hedgehog pathway [2].

Few ecologic studies have shown that UVB exposure and thereby vitamin $D$ synthesis are inversely related to the incidence and mortality of stomach carcinoma [5-12]. However, the correlation between serum vitamin D levels and gastric cancer remains inconsistent [13-18]. Although the relationship between vitamin $D$ status and risk of gastric cancer was indeterminate and only a possible relationship has been suggested in a few studies [17-19], it has not been identified whether there is a de- 
finitive correlation between vitamin D status and clinico-pathologic features of gastric cancer patients.

\section{Aim}

This study was carried out to determine the association of vitamin $D$ levels in patients with gastric adenocarcinoma and to correlate it with the clinico-pathological characters of the disease.

\section{Material and methods}

\section{Study design}

This was a single-centre, prospective, cross sectional study conducted in a tertiary care centre from February 2017 to December 2018. Institute Ethical Committee JIP/IEC/2016/1060 approval and written informed consent were obtained. All ethical principles mentioned in the Declaration of Helsinki were followed in this study. The study was registered under the Clinical Trials Registry of India (CTRI) with the registration number CTRI/2018/05/013825.

\section{Study patients}

All patients above 18 years who were newly diagnosed with gastric adenocarcinoma before undergoing definitive treatment were included in the study. Patients with prior cancer history, patients on vitamin D supplementation, patients with clinical evidence of hyperthyroidism, liver disease (Child $B$ and $C$ ), serum creatinine $>2 \mathrm{mg} / \mathrm{dl}$, and patients who have had neo-adjuvant chemotherapy (NACT) were excluded from the study. The age- and sex-matched controls were recruited from apparently healthy volunteers after obtaining written informed consent.

\section{Sample size}

Assuming an $\alpha$ error of $5 \%$ and power of $80 \%$ and estimated prevalence of vitamin D deficiency/insufficiency in $80 \%$ of cases and $60 \%$ of matched controls from the study by Vyas et al., a sample size of 94 in each group was calculated using Open Epi software version 3.01 [18].

Table I. Vitamin D status in cases and controls

\begin{tabular}{lccc}
$\begin{array}{l}\text { Vitamin D status } \\
\text { [ng/ml] }\end{array}$ & $\begin{array}{c}\text { Cases } \\
(n=94) \\
n(\%)\end{array}$ & $\begin{array}{c}\text { Controls } \\
(n=94) \\
n(\%)\end{array}$ & $P$-value \\
\hline Deficiency $(\leq 20)$ & $83(88)$ & $3(3)$ & $<0.0001^{\#}$ \\
\hline Insufficiency $(21$ to 29$)$ & $10(11)$ & $52(55)$ & \\
\hline Sufficiency $(\geq 30)$ & $1(1)$ & $39(42)$ & \\
\hline Mean \pm SD & $13.83 \pm 5.97$ & $29.15 \pm 4.13$ & $<0.0001^{*}$
\end{tabular}

${ }^{*} \chi^{2}$ test, "Mann-Whitney $U$ test.

\section{Procedure}

Blood samples were collected prior to treatment initiation from patients either admitted for surgery or referred for palliative treatment and 25-hydroxy vitamin D levels (primary outcome parameter) were measured using Siemens AVIDA Centaur Vitamin D Total kits. Demographic details, symptoms, relevant radiographic findings and the proposed treatment plan were entered in the data sheet. The post-operative histopathology reports in patients who underwent surgery were collected. Patients were staged based on the American Joint Committee on Cancer guidelines (AJCC, $8^{\text {th }}$ edition).

The cases and controls were classified into three groups based on serum vitamin $D$ levels: vitamin $D$ deficiency when the level is less than or equal to $20 \mathrm{ng} / \mathrm{ml}$, insufficiency when it is from 21 to $29 \mathrm{ng} / \mathrm{ml}$ and sufficiency when it is greater than or equal to $30 \mathrm{ng} / \mathrm{ml}$ [18-21].

\section{Statistical analysis}

Statistical analysis was done using IBM SPSS 19.0 for Windows. Continuous variables such as age, body weight, symptom duration, BMI, blood sugar, urea, serum creatinine, liver function test, complete blood count, and serum levels of $25(\mathrm{OH})$ vitamin D levels were presented as means with standard deviation. Categorical variables such as gender, co-morbidities, tumour position, differentiation, TNM staging, distant metastasis, smoking and alcoholism were presented as proportions. Continuous variables were compared using Student's $t$ test or the Mann-Whitney $U$ test as appropriate. Categorical variables were analysed using the $\chi^{2}$ test. $P$-values were derived from 2 -sided tests and those less than 0.05 were considered statistically significant.

\section{Results}

We included a total of 188 participants (94 each for cases and controls). The mean age of the case and control groups was comparable $(p=0.808)$. The mean vitamin D level among cases was significantly lower compared to the control group $(13.83 \pm 5.97 \mathrm{ng} / \mathrm{ml}$ vs. $29.15 \pm 4.13 \mathrm{ng} / \mathrm{ml} ; p<0.0001)$. Vitamin D deficiency was significantly higher in cases (88\%) than controls $(3 \%)(p<0.0001)$ (Table I, Figure 1$).$

Among cases, patients above 50 years had a significantly lower mean vitamin D level compared to patients below or equal to 50 years $(13.01 \pm 6.31 \mathrm{ng} / \mathrm{ml}$ vs. 15.66 $\pm 4.70 \mathrm{ng} / \mathrm{ml} ; p=0.026)$. However, there was no significant difference in the mean vitamin $D$ levels among cases with respect to body mass index (BMI), smoking, alcoholism, symptom duration, or loss of weight (Table II). Patients who presented with pain had a significantly lower mean vitamin D level compared to patients who had no pain at presentation $(12.67 \pm 6.35 \mathrm{ng} / \mathrm{ml}$ vs. 


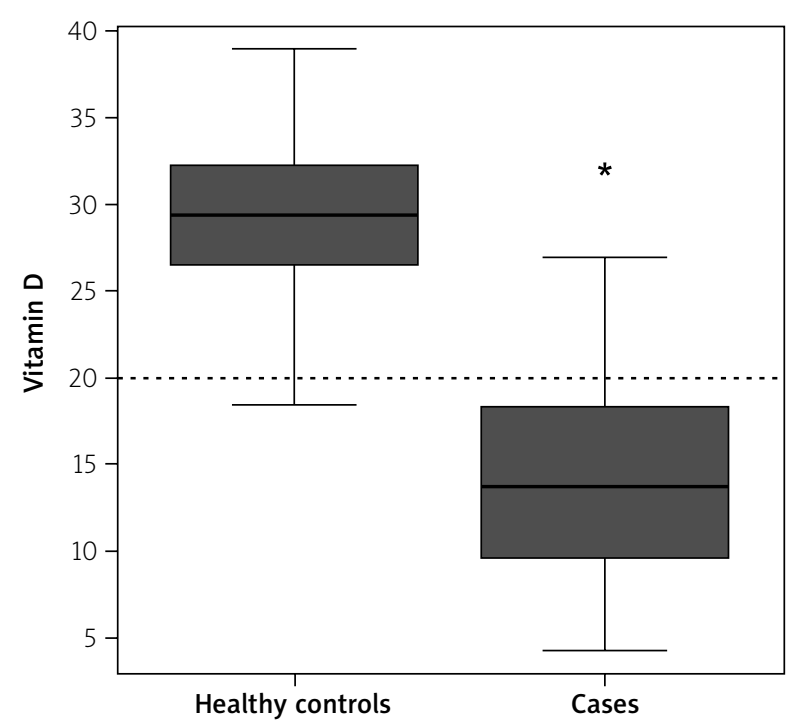

Figure 1. Boxplot showing vitamin D levels of cases (right) and matched control group (left)

$15.39 \pm 5.07 \mathrm{ng} / \mathrm{ml} ; p=0.014)$. The mean vitamin D level in patients presenting without vomiting was significantly lower compared to patients with vomiting (11.52 $\pm 5.81 \mathrm{ng} / \mathrm{ml}$ vs. $14.34 \pm 5.92 \mathrm{ng} / \mathrm{ml} ; p=0.044$ ) (Table III). Cases with $\mathrm{T} 4$ disease had a lower mean vitamin D level compared to cases which had T2 disease on post-operative histopathology (12.83 \pm 6.01 vs $16 \pm 4.99 \mathrm{ng} / \mathrm{ml}$; $p=0.025$ ) (Table IV). Cases with distant metastasis had significantly lower levels of vitamin D compared to non-metastatic cases (9.82 \pm 5.04 vs $14.98 \pm 5.74 \mathrm{ng} / \mathrm{ml}$; $p<0.001$ ) (Table IV). There was an inverse relationship between the clinical stage of gastric adenocarcinoma as per AJCC and mean vitamin D levels in each stage $(p=0.01)$ (Table V). There was no significant relation of vitamin D levels with the location of the tumour, tumour differentiation, or the nodal stage of the disease (Table IV).

\section{Discussion}

The vitamin D cancer hypothesis, introduced by Garland and Garland [22], has gained momentum and has led to a myriad of studies trying to find the molecular basis of vitamin $D$ in tumorigenesis and the possible role of vitamin $D$ in primary prevention of cancers [4]. The protective role of vitamin D in colorectal, breast and prostate cancers has been studied extensively [4, 23, 24]. Various studies have found an inverse relationship between mortality of gastric cancer and ultraviolet-B exposure, which is essential for the synthesis of vitamin D [2]. However, the correlation between serum vitamin D levels and gastric cancer remains equivocal. In the current prospective study, it was found that $88 \%$ of patients with gastric adenocarcinoma were vitamin $\mathrm{D}$ deficient,
Table II. Vitamin D and demographic parameters in patients with gastric cancer

\begin{tabular}{|c|c|c|c|}
\hline Variable & $\begin{array}{c}N=94 \\
n(\%)\end{array}$ & $\begin{array}{c}\text { Vitamin D } \\
\text { mean } \pm S D \\
{[\mathrm{ng} / \mathrm{ml}]}\end{array}$ & $P$-value \\
\hline Age [years]: & & & $0.026^{\star}$ \\
\hline 50 & $29(30.85)$ & $15.66 \pm 4.70$ & \\
\hline$>50$ & 65 (69.15) & $13.01 \pm 6.31$ & \\
\hline Gender: & & & $0.197^{\star *}$ \\
\hline Male & $65(69.15)$ & $14.36 \pm 6.11$ & \\
\hline Female & $29(30.85)$ & $12.63 \pm 5.5$ & \\
\hline Body mass index $\left[\mathrm{kg} / \mathrm{m}^{2}\right]$ : & & & $0.460^{\#}$ \\
\hline 18 & $44(47)$ & $13.05 \pm 5.896$ & \\
\hline$>18$ & $50(53)$ & $14.51 \pm 6.01$ & \\
\hline Smoking: & & & $0.332^{*}$ \\
\hline Yes & $44(47)$ & $14.47 \pm 6.03$ & \\
\hline No & $50(53)$ & $13.26 \pm 5.91$ & \\
\hline Alcoholism: & & & $0.552^{*}$ \\
\hline Yes & $29(30.85)$ & $13.31 \pm 5.17$ & \\
\hline No & $65(69.15)$ & $14.06 \pm 6.31$ & $<0.0001^{\star}$ \\
\hline
\end{tabular}

*Mann-Whitney $U$ test, ${ }^{* *}$ Student's t-test, ${ }^{*} \chi^{2}$ test.

Table III. Vitamin D and symptomatology in patients with gastric cancer

\begin{tabular}{|c|c|c|c|}
\hline Variable & $\begin{array}{c}N=94 \\
n(\%)\end{array}$ & $\begin{array}{c}\text { Vitamin D } \\
\text { mean } \pm S D \\
{[\mathrm{ng} / \mathrm{ml}]}\end{array}$ & $P$-value \\
\hline $\begin{array}{l}\text { Symptom duration } \\
\text { [months]: }\end{array}$ & & & $0.238^{\#}$ \\
\hline$<4$ & $36(38)$ & $15.54 \pm 5.71$ & \\
\hline$\geq 4$ & $58(62)$ & $13.17 \pm 5.97$ & \\
\hline Vomiting: & & & $0.044^{*}$ \\
\hline Yes & $77(82)$ & $14.34 \pm 5.92$ & \\
\hline No & $17(18)$ & $11.52 \pm 5.81$ & \\
\hline Pain: & & & $0.014^{\star}$ \\
\hline Yes & $54(57.45)$ & $12.67 \pm 6.35$ & \\
\hline No & $40(42.55)$ & $15.39 \pm 5.07$ & \\
\hline Loss of weight: & & & $0.742^{\star *}$ \\
\hline Yes & $83(88.30)$ & $13.76 \pm 6.04$ & \\
\hline No & $11(11.70)$ & $14.37 \pm 5.62$ & \\
\hline
\end{tabular}

${ }^{*} \chi^{2}$ test, "Mann-Whitney $U$ test, ${ }^{* *}$ Student's t-test. 
Table IV. Relationship between vitamin D levels and tumour characteristics

\begin{tabular}{|c|c|c|c|}
\hline Variable & $\begin{array}{c}N=94 \\
n(\%)\end{array}$ & $\begin{array}{c}\text { Vitamin D } \\
\text { mean } \pm \text { SD } \\
{[\mathrm{ng} / \mathrm{ml}]}\end{array}$ & $P$-value \\
\hline Location of growth: & & & $0.139^{*}$ \\
\hline Cardia & $11(12)$ & $14.98 \pm 7.11$ & \\
\hline Body & $17(18)$ & $11.27 \pm 5.54$ & \\
\hline Antrum & $66(70)$ & $14.30 \pm 5.78$ & \\
\hline Differentiation: & & & $0.051^{*}$ \\
\hline Well & $14(15)$ & $16.85 \pm 6.11$ & \\
\hline Moderate & $39(41)$ & $14.18 \pm 6.42$ & \\
\hline Poor & $41(44)$ & $12.46 \pm 5.12$ & \\
\hline T stage: & & & $0.025^{\star *}$ \\
\hline $\mathrm{T} 2$ & $10(11)$ & $16 \pm 4.99$ & \\
\hline T3 & $18(19)$ & $16.28 \pm 5.53$ & \\
\hline $\mathrm{T} 4$ & $66(70)$ & $12.83 \pm 6.01$ & \\
\hline N staging: & & & $0.197^{\star \star}$ \\
\hline NO & $10(10.6)$ & $16.33 \pm 5.19$ & \\
\hline N1 & $7(7.4)$ & $13.35 \pm 6.00$ & \\
\hline N2 & $27(28.7)$ & $14.99 \pm 6.63$ & \\
\hline N3 & $50(53.2)$ & $12.76 \pm 5.63$ & \\
\hline Metastasis: & & & $<0.001^{* * \star}$ \\
\hline Present & $21(22)$ & $9.82 \pm 5.04$ & \\
\hline Absent & $73(78)$ & $14.98 \pm 5.74$ & \\
\hline
\end{tabular}

which contrasts with the control population, where $3 \%$ were vitamin D deficient. Among cases, vitamin D levels are significantly associated with age, presence of pain, vomiting, tumour depth, and presence of metastasis.

Some studies did not find any association [13-15], while others found an inverse association between vitamin D levels and gastric cancer [16-18]. Ren et al., in their retrospective study, found an inverse association of vitamin D levels with the clinical stage and with lymph node involvement in patients with gastric adenocarcinoma [19].

The present study found that $55 \%$ of the control population had insufficient vitamin D levels, which is in accordance with the range reported in Indian literature [25]. This insufficiency of vitamin D in controls can be attributed to their dark skin, where melanin acts as a barrier to ultraviolet rays. Dietary factors can
Table V. Vitamin D and clinical stage in patients with gastric cancer

\begin{tabular}{lccc} 
Clinical staging & $\begin{array}{c}\boldsymbol{N}=94 \\
n(\%)\end{array}$ & $\begin{array}{c}\text { Vitamin D } \\
\text { mean } \pm \text { SD } \\
{[\mathrm{ng} / \mathrm{ml}]}\end{array}$ & $P$-value \\
\hline I & $3(3)$ & $19 \pm 6.60$ & \\
\hline II & $14(15)$ & $15.66 \pm 5.03$ & $0.01^{*}$ \\
\hline III & $28(30)$ & $15.30 \pm 4.87$ & \\
\hline IV & $49(52)$ & $12.14 \pm 6.34$ &
\end{tabular}

*Kruskal-Wallis test.

also result in insufficient vitamin D levels [3]. Vitamin D deficiency was found in $88 \%$ of patients with a mean value of $13.83 \pm 5.97 \mathrm{ng} / \mathrm{ml}$. This is lower than the mean vitamin D level observed by Ren et al. $(19.94 \mathrm{ng} / \mathrm{ml})$ in their retrospective study on gastric cancer patients [19].

In the present study, patients older than 50 years had significantly lower levels of vitamin D compared to patients who were younger than 50 years $(p=0.026)$. The mean age of diagnosis of gastric cancer is 60 years and the incidence increases with age [26]. Thus, vitamin D deficiency might play a role in the elderly and might contribute to the predominance of cancers in this age group. On the other hand, factors such as gender, body mass index, smoking or alcoholism were not found to be associated with vitamin $D$ levels. Prior studies have shown conflicting results with respect to gender and body mass index [19, 27], whereas smoking and alcoholism have been found to be not associated with vitamin $D$ levels among patients with gastric adenocarcinoma [19].

Pain in gastric cancer is common in locally advanced and metastatic cases. Patients can also have an ulcer type pain in the very early stages of the disease [28]. Vitamin $D$ has been found to modulate cancer pain, and it has been shown that supplementation with vitamin D alleviates pain in patients undergoing palliation for non-gastric malignancies [29]. With respect to gastric carcinoma, the relationship between pain and vitamin $D$ levels is not elucidated in previous studies which were retrospective [19]. In the current study, it was found that patients presenting with pain had significantly lower levels of vitamin $D$ when compared to patients who did not have pain $(p<0.014)$. This finding suggests that supplementing vitamin D may improve pain in gastric adenocarcinoma.

Patients without vomiting had lower levels of vitamin D compared to patients with vomiting in this study ( $p=0.044)$. Vomiting makes the patient seek medical attention early, and patients without vomiting, mostly but not always, present late compared to patients with 
vomiting. This may be one of the factors influencing the vitamin D levels among cases. This is a new observation in our study and prior retrospective studies have not correlated vomiting with vitamin D levels [19]. Factors such as symptom duration and weight loss, however, were not significantly associated with vitamin $D$ levels. A similar observation concerning symptom duration was reported by Ren et al. [19].

In the current study population, the most common location of gastric cancer was the distal stomach, accounting for $70 \%$ of cases, which is in accordance with the existing Indian literature [30]. There was no significant difference in vitamin $D$ levels with respect to the location of cancer. Prior studies have also found no significant difference in this regard [19, 31].

In the present study, patients with poorly differentiated gastric cancer (44\%) had a lower mean level of vitamin D $(12.46 \pm 5.12 \mathrm{ng} / \mathrm{ml})$ compared with well (14.18 $\pm 6.42 \mathrm{ng} / \mathrm{ml}$ ) and moderately differentiated (12.46 $\pm 5.12 \mathrm{ng} / \mathrm{ml}$ ) groups. However, this was not found to be statistically significant $(p=0.051)$. The role of vitamin $D$ in tumour differentiation is well established in colon and breast cancer. It has been found that poorly differentiated cancers have a lower level of vitamin D compared to well-differentiated variants in colon and breast malignancies [32, 33]. Studies have proven that there is a significant difference in the expression of vitamin $D$ receptors and vitamin $D$ deficiency between premalignant and malignant gastric cancer cells [31, 34]. This might explain the lower levels of vitamin $D$ being associated with poorly differentiated cancer in the current study.

Most of the patients of this study population were in stage T4 (70\%). The mean vitamin D value among patients with $\mathrm{T} 4$ disease $(12.83 \pm 6.01 \mathrm{ng} / \mathrm{ml})$ was significantly lower than in patients with T2 $(16 \pm 4.99 \mathrm{ng} /$ $\mathrm{ml})$ or T3 disease $(16.28 \pm 5.53 \mathrm{ng} / \mathrm{ml})(p=0.025)$. This inverse relationship between vitamin $D$ levels and the T stage of gastric adenocarcinoma was not observed in the study by Ren et al. [19]. This inverse relationship can possibly be attributed to the various molecular signalling pathways controlled by vitamin $D$. It is found that vitamin $D$ controls the proliferation of tumour cells, and a lower level may be associated with poorly differentiated/progressive/locally advanced disease [4, 32]. However, clinical studies have produced equivocal results in this regard, especially in gastric adenocarcinoma [2]. The current study reinforces the definitive role of vitamin $D$ in gastric carcinoma.

The nodal stage was not significantly associated with vitamin D levels in the current study ( $p=0.197)$. This was not the case in other studies comparing nodal stage with vitamin $D$, where a significant difference between N0/N1 disease and N2/N3 disease was found $[19,27]$. A possible explanation for this observation in the current study might be the lower representation N1 disease (7\%).

Gastric carcinoma with distant metastasis to liver, lung, and bone was present in $22 \%$ of cases in this study, and the mean vitamin D level in these cases was significantly lower than in cases without metastasis ( $9.82 \pm 5.04$ vs $14.98 \pm 5.74 \mathrm{ng} / \mathrm{ml} ; p<0.001)$. Pre-clinical studies have proven the role of vitamin $D$ in suppressing distant metastasis by regulating the cell cycle and inducing apoptosis in cancer cells. Vitamin D analogues prevented peritoneal metastasis of gastric adenocarcinoma in animal studies, and their deficiency can lead to disease progression [35]. Clinical studies so far have not confirmed an association between the presence of metastasis and vitamin D levels [19].

Most cases in this study belonged to stage IV (52\%) with a mean vitamin D value of $12.14 \pm 6.34 \mathrm{ng} / \mathrm{ml}$. An inverse relationship was found between the clinical stage and vitamin D levels $(p=0.01)$. A similar observation was noted by Ren et al. in their study [19].

The literature concerning the direct effect of vitamin D supplementation in gastric cancer is scarce. Long-term vitamin D supplementation was found to inhibit Helicobacter pylori infection [36]. Whether the low level of vitamin D observed in these patients is the cause or effect of the disease remains to be elucidated. Considering the findings from this study, patients with advanced gastric carcinoma have significantly lower levels of vitamin D, and future studies on the effect of vitamin D supplementation and its preventive role in gastric adenocarcinoma are essential.

\section{Conclusions}

This study found that vitamin D deficiency is significantly more frequent in patients with gastric adenocarcinoma compared to matched controls. Age, vomiting, and pain were found to be associated with vitamin $D$ levels. There is an inverse relationship between vitamin $D$ levels and the disease characteristics such as the T stage, $M$ stage, and the overall clinical stage of patients with gastric cancer. Thus, vitamin D levels are associated with the clinico-pathological characteristics of gastric adenocarcinoma with a significant deficiency in advanced stages of the disease. However, to assign the causal relationship of vitamin D with disease progression and to study the beneficial effect of vitamin $D$ in gastric cancer further prospective studies are required.

\section{Conflict of interest}

The authors declare no conflict of interest. 


\section{References}

1. Bray F, Ferlay J, Soerjomataram I, et al. Global cancer statistics 2018: GLOBOCAN estimates of incidence and mortality worldwide for 36 cancers in 185 countries. CA Cancer J Clin 2018; 68: 394-424.

2. Du C, Yang S, Zhao X, et al. Pathogenic roles of alterations in vitamin $D$ and vitamin $D$ receptor in gastric tumorigenesis. Oncotarget 2017; 8: 29474-86.

3. Holick MF. Vitamin D deficiency. N Engl J Med 2007; 357: 266-81.

4. Feldman D, Krishnan AV, Swami S, et al. The role of vitamin D in reducing cancer risk and progression. Nat Rev Cancer 2014; 14: 342-57.

5. Grant WB. An estimate of premature cancer mortality in the U.S. due to inadequate doses of solar ultraviolet-B radiation. Cancer 2002; 94: 1867-75.

6. Grant WB. How strong is the evidence that solar ultraviolet B and vitamin $D$ reduce the risk of cancer? An examination using Hill's criteria for causality. Dermatoendocrinology 2009; 1: 17-24.

7. Grant WB. Ecological studies of the UVB-vitamin D-cancer hypothesis. Anticancer Res 2012; 32: 223-36.

8. Grant WB. An ecologic study of cancer mortality rates in Spain with respect to indices of solar UVB irradiance and smoking. Int J Cancer 2007; 120: 1123-8.

9. Grant WB. The likely role of vitamin D from solar ultraviolet-B irradiance in increasing cancer survival. Anticancer Res 2006; 26: 2605-14

10. Mizoue T. Ecological study of solar radiation and cancer mortality in Japan. Health Phys 2004; 87: 532-8.

11. Chen W, Armstrong BK, Rahman B, et al. Relationship between cancer survival and ambient ultraviolet B irradiance in China. Cancer Causes Control 2013; 24: 1323-30.

12. Boscoe FP, Schymura MJ. Solar ultraviolet-B exposure and cancer incidence and mortality in the United States, 1993-2002. BMC Cancer 2006; 6: 264.

13. Lin SW, Chen W, Fan JH, et al. Prospective study of serum 25-hydroxyvitamin D concentration and mortality in a Chinese population. Am J Epidemiol 2012; 176: 1043-50.

14. Pelucchi C, Tramacere I, Bertuccio P, et al. Dietary intake of selected micronutrients and gastric cancer risk: an Italian casecontrol study. Ann Oncol 2009; 20: 160-5.

15. Chen W, Dawsey SM, Qiao YL, et al. Prospective study of serum $25(\mathrm{OH})$-vitamin $\mathrm{D}$ concentration and risk of oesophageal and gastric cancers. Br J Cancer 2007; 97: 123-8.

16. Abnet CC, Chen Y, Chow WH, et al. Circulating 25-hydroxyvitamin D and risk of esophageal and gastric cancer: Cohort Consortium Vitamin D Pooling Project of Rarer Cancers. Am J Epidemiol 2010; 172: 94-106.

17. La Vecchia C, Ferraroni M, D'Avanzo B, et al. Selected micronutrient intake and the risk of gastric cancer. Cancer Epidemiol Biomarkers Prev 1994; 3: 393-8.

18. Vyas N, Companioni RC, Tiba M, et al. Association between serum vitamin $D$ levels and gastric cancer: a retrospective chart analysis. World J Gastrointest Oncol 2016; 8: 688-94.

19. Ren C, Qiu M, Wang D, et al. Prognostic effects of 25-hydroxyvitamin D levels in gastric cancer. J Transl Med 2012; 10: 16.

20. Bischoff-Ferrari HA. Optimal serum 25-hydroxyvitamin D levels for multiple health outcomes. Adv Exp Med Biol 2014; 810: 500-25.
21. Holick MF. Vitamin D status: measurement, interpretation, and clinical application. Ann Epidemiol 2009; 19: 73-8.

22. Garland CF, Garland FC. Do sunlight and vitamin D reduce the likelihood of colon cancer? Int J Epidemiol 1980; 9: 227-31.

23. Lee JE, Li H, Chan AT, et al. Circulating levels of vitamin D and colon and rectal cancer: the Physicians' Health Study and a meta-analysis of prospective studies. Cancer Prev Res Phila Pa 2011; 4: 735-43.

24. Estébanez N, Gómez-Acebo I, Palazuelos C, et al. Vitamin D exposure and risk of breast cancer: a meta-analysis. Sci Rep 2018; 8: 9039.

25. Harinarayan CV, Ramalakshmi T, Venkataprasad U. High prevalence of low dietary calcium and low vitamin D status in healthy south Indians. Asia Pac J Clin Nutr 2004; 13: 359-64.

26. Ajani JA, Lee J, Sano T, et al. Gastric adenocarcinoma. Nat Rev Dis Primer 2017; 3: 17036.

27. Obermannova R, Valik D, Hasenclever D, et al. High prevalence of severe hypovitaminosis $D$ in patients with advanced gastric cancer treated with first-line chemotherapy with or without anti-EGFR-directed monoclonal antibody (EXPAND trial) showing no prognostic impact. Eur J Cancer 2019; 116: 107-13.

28. Maconi G, Manes G, Porro GB. Role of symptoms in diagnosis and outcome of gastric cancer. World J Gastroenterol 2008; 14: 1149-55.

29. Helde-Frankling M, Höijer J, Bergqvist J, Björkhem-Bergman L. Vitamin D supplementation to palliative cancer patients shows positive effects on pain and infections - results from a matched case-control study. PLoS One 2017; 12: e0184208.

30. Servarayan Murugesan C, Manickavasagam K, Chandramohan A, et al. Gastric cancer in India: epidemiology and standard of treatment. Updat Surg 2018; 70: 233-9.

31. Wen $Y$, Da M, Zhang Y, et al. Alterations in vitamin D signaling pathway in gastric cancer progression: a study of vitamin $D$ receptor expression in human normal, premalignant, and malignant gastric tissue. Int J Clin Exp Pathol 2015; 8: 13176-84.

32. Cross HS, Bareis $P$, Hofer $H$, et al. 25-Hydroxyvitamin D(3)-1alphahydroxylase and vitamin $D$ receptor gene expression in human colonic mucosa is elevated during early cancerogenesis. Steroids 2001; 66: 287-92.

33. Karthikayan A, Sureshkumar S, Kadambari D, et al. Low serum 25-hydroxy vitamin $D$ levels are associated with aggressive breast cancer variants and poor prognostic factors in patients with breast carcinoma. Arch Endocrinol Metab 2018; 62: 452-9.

34. Singh K, Gandhi S, Batool R. A Case-control study of the association between vitamin $D$ levels and gastric incomplete intestinal metaplasia. Nutrients 2018; 10: 629.

35. Park MR, Lee JH, Park MS, et al. Suppressive effect of 19-nor$1 \alpha$-25-dihydroxyvitamin D2 on gastric cancer cells and peritoneal metastasis model. J Korean Med Sci 2012; 27: 1037-43.

36. Kawaura A, Takeda E, Tanida N, et al. Inhibitory effect of long term 1alpha-hydroxyvitamin D3 administration on Helicobacter pylori Infection. J Clin Biochem Nutr 2006; 38: 103-6.

Received: 31.08 .2020

Accepted: 21.09 .2020 